\title{
Clavicle Fracture with Injury of Subclavian Artery and Brachial Plexus: Case Report
}

\author{
Zhiqiang Zhou ${ }^{1 \#}$, Peng Zhang ${ }^{1 \#, ~ B i n g c h e n ~ S h a n ~}{ }^{1}$, Aimin Qian², Jie Yang ${ }^{3}$ and Xiaozhong Zhou ${ }^{1 *}$ \\ ${ }^{1}$ Department of Orthopedics, Second Affiliated Hospital of Soochow University, Suzhou, China \\ ${ }^{2}$ Vascular Surgery, Second Affiliated Hospital of Soochow University, Suzhou, China \\ ${ }^{3}$ VIP Ward, Second Affiliated Hospital of Soochow University, Suzhou, China
}

\#Drs Zhiqiang Zhou and Peng Zhang have contributed equally to this work

*Corresponding author: Xiaozhong Zhou, Department of Orthopedics, Second Affiliated Hospital of Soochow University, Suzhou, China

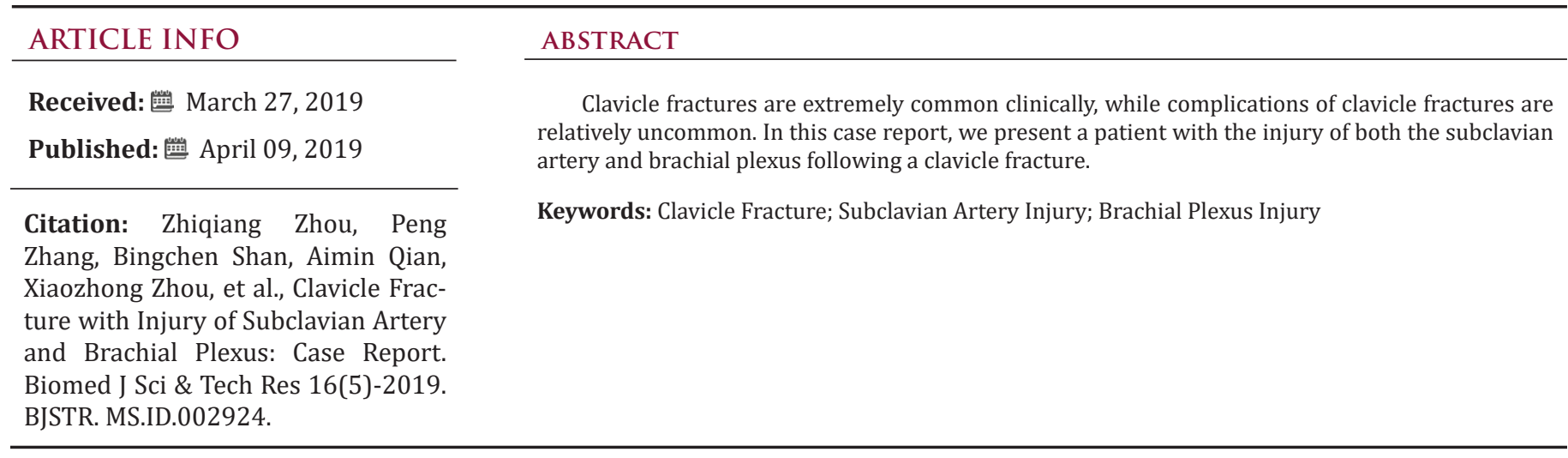

\section{Introduction}

Clavicle fractures are extremely common, accounting for up to $2.6-12 \%$ of all fractures [1-4] and $44-66 \%$ of all fractures about the shoulder. Clavicle fractures have several classification schemes [2,5-8] and are generally classified into three groups based on their locations [6]. Fractures of the middle third, or midshaft of the clavicle, classified as group I, are the most commonly encountered, accounting for up to $80 \%$ of all clavicle fractures $[1,9]$. Fractures of the distal third or acromial end of the clavicle, consisting of $15 \%$ of clavicle fractures, are classified as group II, and fractures of the medial third or sternal end are classified as group III, making up $5 \%$ of injuries. Complications of clavicle fractures are relatively uncommon and include mal-union, non-union, nerve paresthesia, brachial plexus neuropathy, thoracic outlet syndrome, pneumothorax, and vascular injuries [10]. Damage to the neurovascular structure associated with closed fractures of the clavicle is rare $[11,12]$ and usually related to penetrating traumas [13-16]. In this case report, we present a patient with the injury of both the subclavian artery and brachial plexus following a clavicle fracture. Our case report is unique as it presents a combination of two rare complications of clavicle fractures.

\section{Case Report}

A 45-year-old man presented into the Emergency of our hospital after experiencing right shoulder pain with progressive motor and sensory dysfunction of right upper extremity. 12hours before the presentation, the patient had a fallen accident while riding a bike. Diagnosed right middle third clavicle fracture with a bone fragment downward which was shown on X-ray in the local hospital, the patient progressively underwent a sensomotor loss. Four hours after the accident, he appeared an aggravating numbness and motor dysfunction. Eight hours then, he lost the sensory and motor ability of the right upper extremity completely. Then the patient was transferred to our hospital for further treatment. Admission examination: swelling right shoulder, chest and neck, subcutaneous congestion and bruising, localized tenderness (+), and bone rubbing sign. Activity was limited in the right shoulder, right upper extremity sensation disappeared, right upper limb muscle strength level $0 / 5$, right radial artery pulse unpalpated, right upper limb skin temperature normal. X-ray: right middle third clavicle fracture (Figure 1). Diagnosis: right clavicle fracture with nervous and vascular injury. 


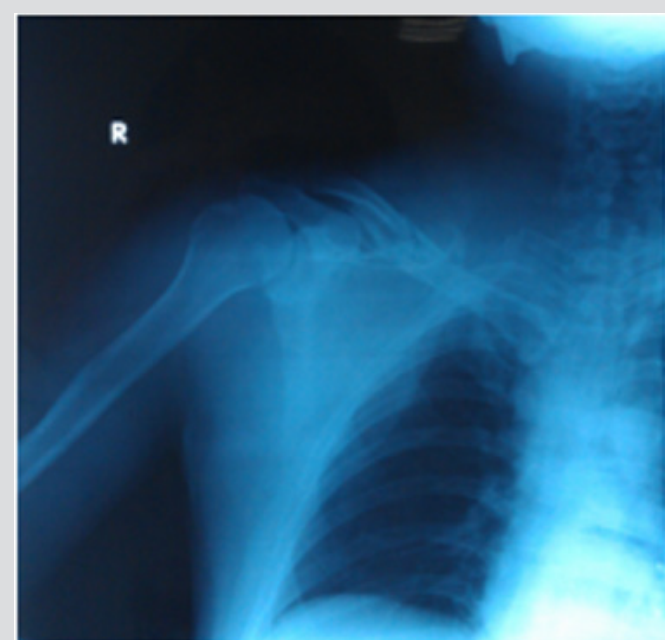

Figure 1: pre-operative X-ray (2013-3-18).

Treatment: Clavicular fracture with plate fixation, and subclavian artery, vein and brachial plexus repair. During the operation, we found right middle third clavicle comminuted fracture with four fragments and subclavian tissue swelling significantly, and we palpated the proximal arterial pulse while the distal arterial pulse was untouched. Thus, we deduced that the subclavian artery ruptured by the broken fracture that caused the distal artery stopped (Figure 2). We had proximal clavicular osteotomy to expose the blood vessels area. Once the blocked fracture was removed, the artery jetted out and blood pressure dropped sharply to $75 / 54 \mathrm{mmHg}$, and the heart rate rose to 112 beats/ min. Immediately gauzes were packed to stop bleeding. With the help of the autologous blood transfusion and homotypic blood transfusion, we took the comminuted fracture block out, finding subclavian artery ruptured and brachial plexus injured severely. After subclavian artery anastomosis, patient blood pressure rose to $80 / 68 \mathrm{mmHg}$, heart rate dropped to 105 beats/min and the right upper limb artery fluctuations can be touched.

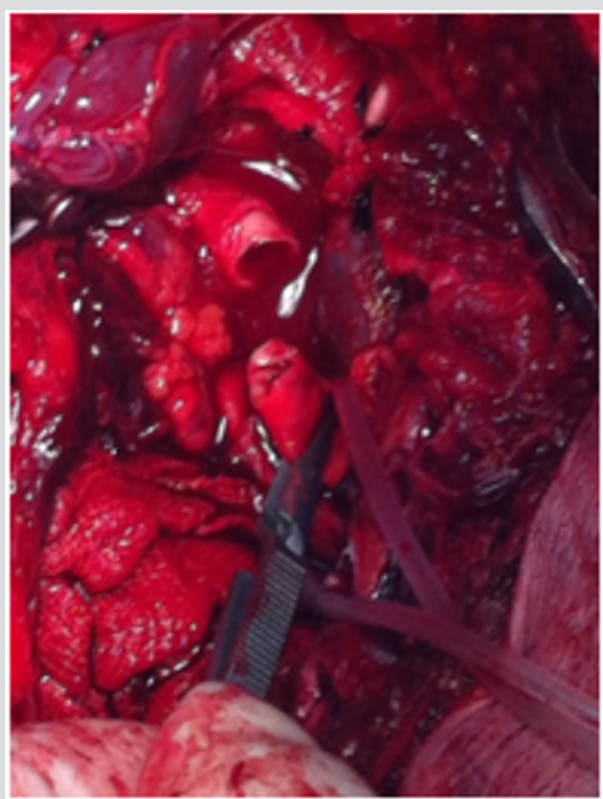

Figure 2: Ruptured subclavian artery during operation.
Then we reduced the fracture as a whole and fixed with clavicle locking plate. In total, blood loss was about $4500 \mathrm{ml}$ and blood transfusion were $3000 \mathrm{ml}$ autologous blood transfusion and MAP 27U homotypic blood transfusion. Antibiotic, anticoagulation and neurotrophic drugs were used post-operatively. One month later, the patient's follow-up revealed no sign of neural recovery with motor and sensory complete dysfunction of right upper extremity. Right clavicle X-ray was seen in Figure 3. Right upper extremity vascular ultrasound showed: subclavian artery and vein normal. Electromyography for right up extremity demonstrated : right brachial plexus root damage, C5-7damage, C8-T1 stem damage. Thus, plate fixation and bone graft was performed after admission, and he was discharged from our hospital after symptomatic treatment for 8 days post-operatively. Right clavicle X-ray was performed post-operatively (Figure 4).

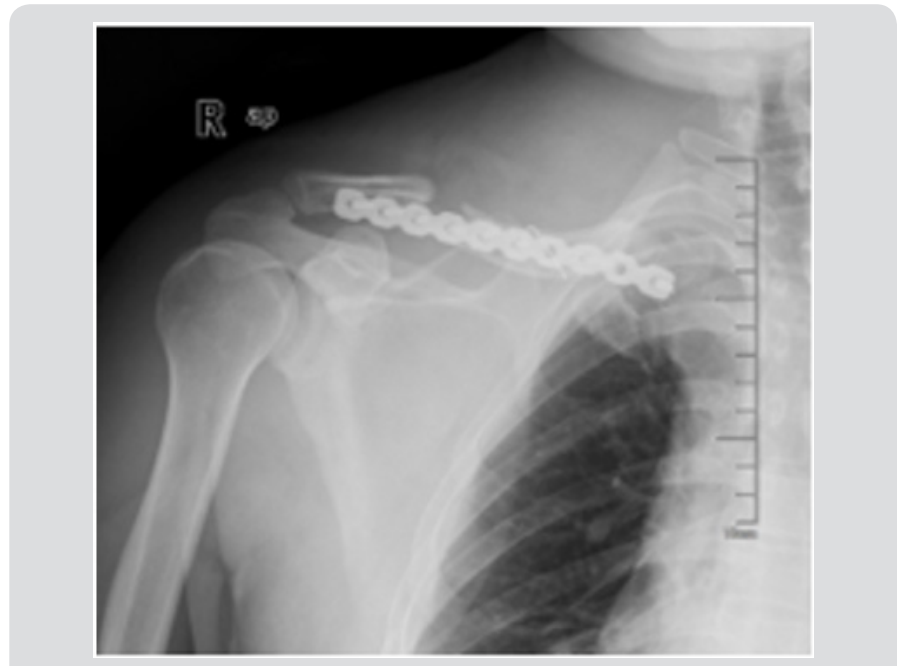

Figure 3: Post-operative X-ray.

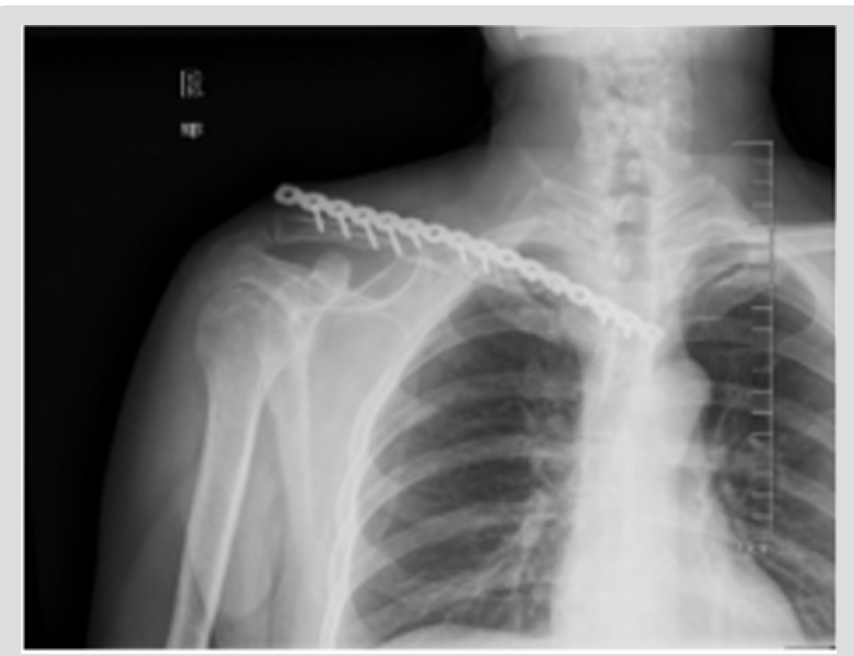

Figure 4: Post-operative X-ray.

The patient sustained complete loss of sensation and motor power of his right upper extremity for six months after the second operation, and then the sensory and motor function was restored gradually. Follow-up X-ray of our hospital in November 2014 was performed (Figure 5). After that, he exercised his arm every day. He could hold some heavy stuff using his right hand in 2015 and his muscle strength resumed almost completely in 2016. He came 
to the out-patient clinic in our hospital for follow-up in November 2017 (Figure 6) without any apparent chief complaint. Physical examination: right upper extremity hypoesthesia, right upper limb muscle strength level 5/5, right radial artery pulse palpated, five proximal interphalangeal joints straightening limitation (Figure 7a7f). X-ray: right clavicle plate rupture (Figure 6). Electromyography:

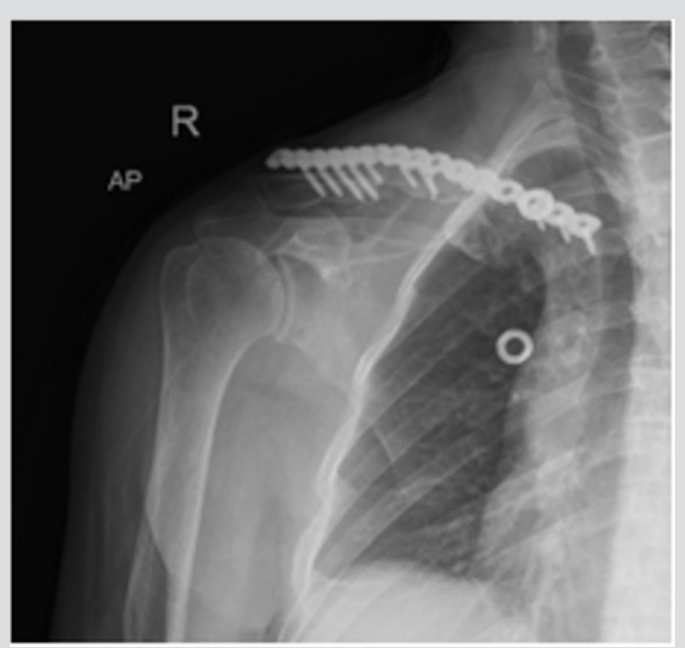

Figure 5: X-ray of 18 months follow-up.

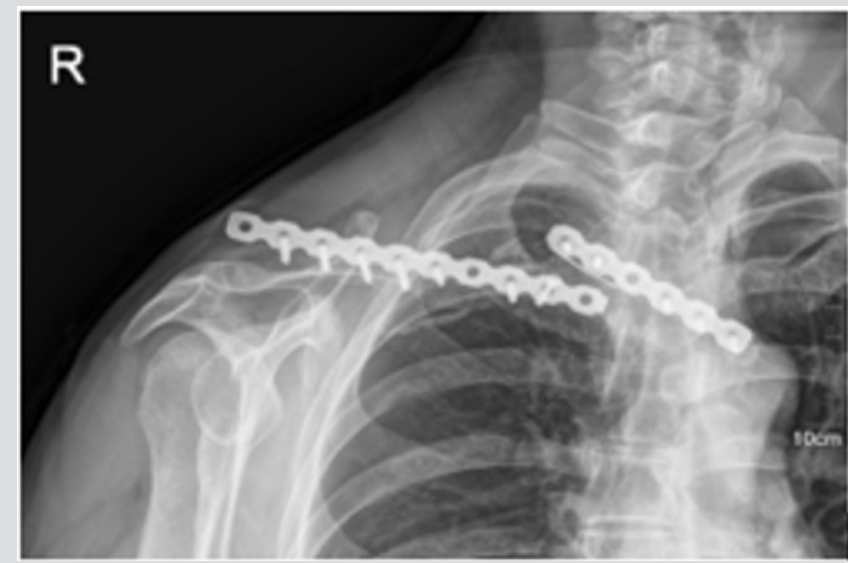

Figure 6: X-ray of 51 months follow-up.

a) Right upper extremity mcv: cmap amplitudes of right median nerve, right ulnar nerve, right radial nerve, right axillary nerve and right musculocutaneous nerve all decreased;

b) right upper limb scv: right median nerve and right ulnar nerve were not detected

c) needle electromyography: many positive sharp waves appeared in the right extensor pollicis brevis during resting state;

d) Conclusion: neurogenic deficit of right upper limb (all brachial plexus injury).

\section{Discussion}

Clavicle fracture is one common clinical fracture, and the comminuted fragment may pierce subclavian vessels and nerves, which makes small odds for life salvage. Vascular complications of clavicle fracture are rare and are generally recognized as an early complication due to transection of the vein by a displaced fracture of the mid-shaft or lateral end [16-18] or by a late complication $[3,19]$, secondary to the compression caused by abundant callus formation. Brachial plexus injury following clavicle fracture is generally a delayed phenomenon occurring days, weeks and even months after the original lesion [20-23]. In this case, the neurological symptoms were progressing rapidly over a few hours. The fracture injured subclavian artery and the brachial plexus. Because the fragments inserted in the artery wall, vasomotoric symptoms were not that obvious at the time of injury. During the surgery, we found exposing the injured blood vessel and nerves directly was difficult, thus first step we truncated the proximal clavicular, therefore, finding the ruptured vessel and nerves could be easier. Secondly, we had subclavian artery anastomosis and then fracture reduction and fixation.

Some scholars reported that clavicle fracture with subclavian artery rupture needed exploratory thoracotomy [24], while in this article, we used the orthopedic incision to finish it with the help of vascular surgeon, yet with great difficulties and it required good skills and technique. It also avoided the great loss of blood and trauma from open chest operation, which was vitally important for life saving. Reviewing the treating process, we did not do the angiography exam before operation, thus blood loss was evaluated improperly, thanks for the sufficient preoperative blood preparation, and the utilization of autologous blood transfusion which provided important protection for saving.

\section{References}

1. Postacchini F, Gumina S, De Santis P, Albo F (2002) Epidemiology of clavicle fractures. Journal of Shoulder and Elbow Surgery 11(5): 452456

2. Nordqvist A, Petersson C (1994) The incidence of fractures of the clavicle. Clinical orthopaedics and related research (300): 127-132.

3. Kitsis CK, Marino AJ, Krikler SJ, Birch R (2003) Late complications following clavicular fractures and their operative management. Injury 34(1): 69-74.

4. Raviraja A, Chandrashekar CM, Roshan SD, and Srinivas JV (2009) Subclavian artery and vein injury following clavicle fracture due to blunt trauma. Injury Extra 40: 36-38.

5. Robinson CM (1998) Fractures of the clavicle in the adult Epidemiology and classification. The Journal of bone and joint surgery British volume $80(3): 476-484$

6. Allman FL (1967) Fractures and ligamentous injuries of the clavicle and its articulation. The Journal of bone and joint surgery. American volume 49(4): 774-784.

7. Neer CS (1963) Fracture of the distal clavicle with detachment of the coracoclavicular ligaments in adults. The Journal of trauma 3: 99-110.

8. Neer CS (1968) Fractures of the distal third of the clavicle. Clinical orthopaedics and related research 58: 43-50.

9. Duan X, Zhong G, Cen S, Huang F, Xiang Z, et al. (2011) Plating versus intramedullary pin or conservative treatment for midshaft fracture of clavicle: a meta-analysis of randomized controlled trials. J Shoulder Elbow Surg 20(6): 1008-1015.

10. Cooney DR, Kloss B (2012) Case report: Delayed subclavian vein injury secondary to clavicular malunion. The Journal of emergency medicine 43(4): 648-650.

11. Hill JM, McGuire MH, Crosby LA (1997) Closed treatment of displaced middle-third fractures of the clavicle gives poor results. The Journal of bone and joint surgery. British volume 79(4): 537-539. 
12. Hutchinson MR, Ahuja GS (1996) Diagnosing and treating clavicle injuries. The Physician and sportsmedicine. 24: 26-36.

13. Costa MC, Robbs JV (1988) Nonpenetrating subclavian artery trauma Journal of vascular surgery 8(1): 71-75.

14. Katras T, Baltazar U, Rush DS, Davis D, Bell T D, et al. (2001) Subclavian arterial injury associated with blunt trauma. Vascular surgery 35(1): 4350

15. Kendall KM, Burton JH, Cushing B (2000) Fatal subclavian artery transection from isolated clavicle fracture. The Journal of trauma 48(2): 316-318.

16. Natali J, Maraval M, Kieffer E, Petrovic P (1975) Fractures of the clavicle and injuries of the sub-clavian artery Report of 10 cases. The Journal of cardiovascular surgery 16(5): 541-547.

17. Lefrant JY, Pandolfi JL, Bénézet JF, Gouze C, Saïssi G, et al. (1995) Catheterisme De La Veine Sous-Claviere Sous Controle Doppler. Annales Françaises Danesthésie Et De Réanimation 14: R269.

18. Kochhar T, Jayadev C, Smith J, Griffiths E, Seehra K, et al. (2008) Delayed presentation of Subclavian venous thrombosis following undisplaced clavicle fracture. World journal of emergency surgery WJES 3: 25.

\section{ISSN: 2574-1241}

DOI: 10.26717/BJSTR.2019.16.002924

Xiaozhong Zhou. Biomed J Sci \& Tech Res

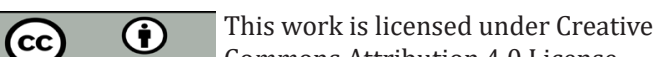

Submission Link: https://biomedres.us/submit-manuscript.php
19. Penn I (1964) The Vascular Complications of Fractures of The Clavicle. The Journal of trauma 4: 819-831.

20. Derham C, Varghese M, Deacon P, Spencer N, Curley P, et al. (2007) Brachial plexus palsy secondary to clavicular nonunion. The Journal of trauma 63(4): E105-107

21. Rumball KM, Da Silva VF, Preston DN, Carruthers CC (1991) Brachialplexus injury after clavicular fracture: case report and literature review. Canadian journal of surgery Journal canadien de chirurgie 34(3): 264266.

22. Barbier O, Malghem J, Delaere O, Vande Berg B, Rombouts JJ, et al. (1997) Injury to the brachial plexus by a fragment of bone after fracture of the clavicle. The Journal of bone and joint surgery British volume 79(4): 534-536.

23. Lin CC, Lin J (2009) Brachial plexus palsy caused by secondary fracture displacement in a patient with closed clavicle fracture. Orthopedics $32(10)$.

24. Faisham WI, Mohammad P, Juhara H, Munirah NM, Shamsulkamaruljan $\mathrm{H}$, et al. (2011) Clavicle fracture and subclavian vessels disruption with massive haemothorax mimic intrathoracic injury. The Malaysian journal of medical sciences: MJMS 18(2): 74-77.

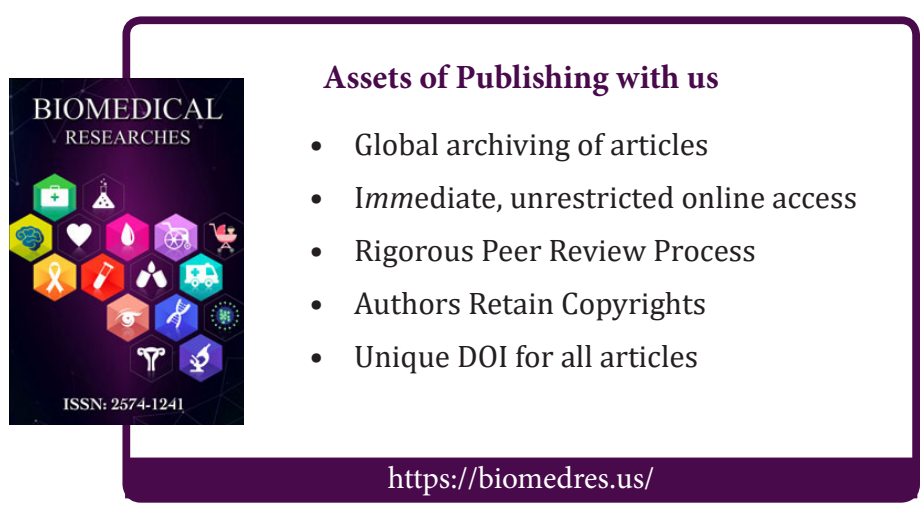

